\title{
The clinical communication and information challenges associated with the psychosexual aspects of prostate cancer treatment
}

Dol:

10.1016/j.socscimed.2017.05.011

\section{Document Version}

Accepted author manuscript

Link to publication record in Manchester Research Explorer

Citation for published version (APA):

Speer, S., Tucker, S., Mcphillips, R., \& Peters, S. (2017). The clinical communication and information challenges associated with the psychosexual aspects of prostate cancer treatment. Social Science and Medicine, 185, 17-26. https://doi.org/10.1016/j.socscimed.2017.05.011

Published in:

Social Science and Medicine

\section{Citing this paper}

Please note that where the full-text provided on Manchester Research Explorer is the Author Accepted Manuscript or Proof version this may differ from the final Published version. If citing, it is advised that you check and use the publisher's definitive version.

\section{General rights}

Copyright and moral rights for the publications made accessible in the Research Explorer are retained by the authors and/or other copyright owners and it is a condition of accessing publications that users recognise and abide by the legal requirements associated with these rights.

\section{Takedown policy}

If you believe that this document breaches copyright please refer to the University of Manchester's Takedown Procedures [http://man.ac.uk/04Y6Bo] or contact uml.scholarlycommunications@manchester.ac.uk providing relevant details, so we can investigate your claim.

\section{OPEN ACCESS}


This is the authors' final, pre-publication version of the paper to be published in the journal, Social Science \& Medicine. Some small changes may have occurred after this version was sent to publication. The final published version should be consulted before quoting or discussing in detail.

The clinical communication and information challenges associated with the psychosexual aspects of prostate cancer treatment

\section{Susan A Speer, Samantha R Tucker, Rebecca McPhillips ${ }^{1}$, \& Sarah Peters.}

School of Health Sciences, The University of Manchester, Oxford Road, Manchester, UK, M13 9PL

susan.speer@manchester.ac.uk (S.A. Speer).

samantharayetucker@aol.co.uk (S.R. Tucker)

rebecca.mcphillips@mhsc.nhs.uk (R. McPhillips)

sarah.peters@manchester.ac.uk (S.Peters)

Corresponding author: Dr Susan A. Speer, School of Health Sciences, Coupland Building 1, The University of Manchester, Oxford Road, Manchester M13 9PL, UK.

Tel.: +4401612752590

E-mail address: susan.speer@manchester.ac.uk (S.A. Speer).

\footnotetext{
${ }^{1}$ Present: MHSCT Research \& Innovation, Rawnsley Building, Manchester Royal Infirmary, Hathersage Road, Manchester M13 9WL
} 


\title{
The clinical communication and information challenges associated with the psychosexual aspects of prostate cancer treatment
}

\begin{abstract}
Rationale: Prostate cancer and its treatment have significant sexual side effects that necessitate timely patient information and open communication with healthcare professionals. However, very little is known about men's experiences of talking to clinicians about the psychosexual difficulties associated with the disease.

Objective: This study aims to advance understanding of men's perceptions of the communication and information challenges associated with the psychosexual aspects of prostate cancer and its treatment.
\end{abstract}

Method: Between October 2013 and April 2014, semi-structured interviews were conducted with 21 men from the UK who had been treated for prostate cancer. Interview transcripts were analysed using thematic analysis.

Results: Three themes describe the communication challenges men face: (1) It can be too soon to talk about sex; (2) The psychology of sex is missing; (3) Communication is not individually tailored.

Conclusions: Clinicians might usefully (1) consider and discuss with patients how their psychosexual communication needs and information processing abilities may fluctuate across the cancer timeline; (2) initiate discussions about the consequences of treatment that extend beyond biological and mechanical aspects to include emotional and relational factors; (3) tailor communication to the dynamic mix of attributes that shape men's individual psychosexual needs, including their relationship status, sexual orientation, sexual motivations and values. Skills-based training in communication and psychosexual awareness may facilitate the proactive 
and permissive stance clinicians need to discuss sexual side effects with a heterogeneous group of patients.

Key words: United Kingdom; Qualitative; Interviews; Sex; Sexuality; Side effects; Thematic analysis; Psychology.

\section{Research highlights}

- Study examines the psychosexual communication challenges faced by men with PC

- Thematic analysis of 21 interviews with men who have undergone active treatment

- Three psychosexual communication challenges are identified

- Challenges relate to lack of individualised, contextually-based communication

- Findings recommend communication is sensitised towards men's individual needs 


\section{Introduction}

Prostate cancer (PC) is one of the most prevalent forms of cancer in the developed world, with an estimated 1.1 million cases diagnosed worldwide in 2012 (Ferlay et al. 2015). There is a strong age component to the etiology of PC, with most cases occurring in men aged 50 years and older (Prostate Cancer UK [PCUK], 2013). Incidence has increased significantly in recent years, due to an ageing population and wider availability of the prostate specific antigen screening test (Quinn and Babb, 2002). In the UK, it is estimated that one in eight men will get PC at some point in their lives (PCUK, 2013). However, survival rates are favourable: In the USA, following active treatment, the 5-, 10- and 15-year cancer specific survival rates are 95\%, 90\%, and 79\%, respectively (Ward, Slezak, Blute, Bergstralh \& Zincke, 2005). Consequently, the disease constitutes a significant 'public health burden', with management of treatment-related sexual side effects posing 'a particular challenge' (Forbat, White, Marshall-Lucette \& Kelly, 2012, p.98).

Men diagnosed with PC face difficult choices between treatment options that can result in incontinence, infertility, feminisation, and chronic changes to sexual functioning, including erectile dysfunction, penile atrophy, and loss of libido (Chung and Brock, 2013; Donovan et al., 2016; PCUK, 2012).

For many, these side effects will 'be less acceptable than the disease itself' (National Institute for Health and Care Excellence [NICE], 2014, p.117), causing chronic psychological distress (Wootten \& Siddons, 2013), difficulties with body image, masculinity and self-esteem (Harrington, 2011; Oliffe, 2005), and impaired quality of current and future partner/marital relationships and sexual intimacy (Beck, Robinson \& Carlson, 2009; Penson and Nelson, 2009; see also Tucker, Peters \& Speer, 2016). 
The unique psychosexual challenges posed by PC and its treatment means that a man's trajectory from diagnosis through treatment, to post-treatment and recovery, is a difficult and complex journey that necessitates collaborative and open communication with healthcare professionals (Brandenburg and Bitzer, 2009; Hordern and Street, 2007). Effective communication 'profoundly affects' a patient's cancer experience (Department of Health, 2011, p.48; Independent Cancer Taskforce, 2015): It can promote patient satisfaction, psychological functioning and overall health outcomes, including cancer survivorship (Arora, 2003; Epstein and Street, 2007; Fallowfield and Jenkins, 1999; National Cancer Survivorship Initiative, 2013; Street, Makoul, Arora \& Epstein, 2009). Consequently, UK guidelines and policy directives recommend that healthcare professionals must be adequately skilled in communication to support patients and empower them to make informed decisions about their care (Department of Health, 2011; Independent Cancer Taskforce, 2015; NICE, 2014). This includes the need to provide men and their partners with adequate, tailored information about the sexual consequences of treatment decisions, focusing on quality of life as well as survival (NICE, 2014, p.14). Specifically, patients should be informed about the impact of treatment 'on their sexual function, physical appearance, continence and other aspects of masculinity' (NICE, 2014, p.14; PCUK, 2012, p.15), and be offered 'the opportunity to talk to a healthcare professional experienced in dealing with psychosexual issues at any stage of the illness and its treatment' (NICE, 2014, p.14).

Evidence suggests that there is variability in how well this is achieved in clinical practice and that clinicians inadequately address cancer patients' sexual information and support needs (Tucker, Peters \& Speer, 2016; Flynn et al., 2012; 
Gilbert, Perz and Ussher, 2016; NICE, 2014, p. 115ff; Ussher et al., 2013; Watson et al., 2015; Zhou et al., 2016). For example, in their observational study of communication in British PC clinics, Forbat et al. (2012, p.98) note that patients' psychosexual concerns are often side-lined by clinicians, with limited opportunities 'to discuss the specific impact of prostate cancer and its treatments on sexual functioning'.

Clinicians may be reticent to talk about psychosexual issues with cancer patients because they lack sufficient time, knowledge, confidence and comfort, think it is someone else's responsibility, or assume a patient's age or relationship status render sexual concerns irrelevant (Hordern and Street, 2007; Park, Norris \& Bober, 2009; Ussher et al., 2013). Likewise, patients may be reluctant to disclose psychosexual concerns due to embarrassment and perceptions that clinicians lack the time to discuss such issues, regarding them as trivial compared with survival (e.g., Carr, 2007; Flynn et al., 2012; Stead, Brown, Fallowfield, \& Selby, 2003). To date, no study has specifically asked men about their experiences of talking to clinicians about the psychosexual aspects of PC and its treatment. This study aims to address this gap, generating new understandings of the psychosexual information and communication challenges faced by men with PC.

\section{Methods}

We adopted a qualitative, semi-structured interview-based approach to give men the freedom to reflect upon and describe their experiences of talking to clinicians in their own words (Barriball and While, 1994). Ethical approval was granted by the University of Manchester Research Ethics Committee. Participants were 21 men aged 18 years or over who had received a diagnosis of PC and were undergoing or 
had undergone active treatment. Participants were excluded from the study if they had untreated PC or their disease was managed by expectant management (watchful waiting) or active surveillance. Based on previous research, an interview sample of 20 patients is optimal for achieving data saturation (Speer and McPhillips, 2013). Most men $(n=17)$ described their stage of disease as localised or locally advanced wherein the cancer had grown just outside of the prostate gland but was not metastatic. The remainder $(n=4)$ had advanced, metastatic cancer. All participants were English speakers and able to provide written informed consent. Participants were White-British and ranged in age from 52 to 78 years. Further demographic and clinical details are presented in Table 1.

\section{[Table 1 about here]}

At the outset the research team did not know how difficult it might be to recruit men willing to discuss psychosexual communication needs with researchers. Therefore, in order to maximise sample size, participants were recruited using opportunity and snowball sampling methods: First, potential participants were identified by SS, who had existing contacts from patient and public involvement work in the community. These men had consented to being contacted to take part in future research. One of these existing contacts identified as an advocate for gay men within the PC community. He was specifically approached to participate in this study in view of calls for research that examines the communication experiences of gay men with PC (Tucker, Peters \& Speer, 2016). Participants were also identified through the PC Support Federation registry of patient-led support groups in the Northwest of England. Written details of the study were disseminated by support 
group facilitators on behalf of the researchers or consent was granted by facilitators for the researchers to attend and present the study to potential participants.

Between October 2013 and April 2014, two female researchers (ST or RM) conducted in-depth, semi-structured interviews with 21 men, five of whom were accompanied, at their request, by their female partner who also gave their consent and actively participated in the interview. The interview guide was informed by public involvement work in the community. It was divided into three sections: (1) Background, in which disease history and treatment were discussed; (2) questions about general clinical communication and information needs; (3) questions about clinical communication and information needs in respect of the psychosexual aspects of prostate cancer and its treatment. See online supplement for interview guide.

Participants were interviewed in their preferred location and paid $£ 20$ for their time. Each audio-recorded interview lasted between 50 and 170 minutes, was transcribed verbatim, and identifying details changed.

Transcripts were analysed qualitatively using thematic analysis to identify the core patterns within men's descriptions (Braun and Clarke, 2006). Coding and theme development proceeded in an inductive fashion without reference to a preexisting model or frame (Boyatzis, 1998; Braun and Clarke, 2006). Transcripts were read and re-read, with initial ideas noted. Interesting features of the data were systematically coded at the descriptive, semantic level, reflecting men's own language, meaning, and concepts (Braun and Clarke, 2006). Using the list of all identified codes, those that were similar were clustered to create sub-themes. Finally, sub-themes that represented patterns were collated to form themes. 
Reliability was enhanced through an iterative process in which authors discussed and refined codes and themes until they reached agreement (Boyatzis, 1998). Themes were subject to ongoing analysis and refinement to ensure they were cohesive against the coded extracts and data set.

\section{Results}

The analysis identified three themes that describe the predominant information and clinical communication challenges men face in respect of the psychosexual aspects of prostate cancer and its treatment:

(1) It can be too soon to talk about sex;

(2) The psychology of sex is missing;

(3) Communication is not individually tailored.

A model of themes and sub-themes is presented in Figure 1.

[Figure 1 about here]

\section{(1) It can be too soon to talk about sex}

Men described the initial aftermath following diagnosis as the point in their cancer journey when they received the most information (both written and verbal), about the sexual side effects of treatment and how these could be managed. Men reported that their treatment options and associated side-effects, were presented to them during individual consultations with clinicians from different treatment specialities, with each clinician essentially 'selling' (Paul) their particular treatment to the patient. Although men were mindful of the need to be well informed about sexual 
side effects, they reported that this information came at a point when they were already overwhelmed and shocked by their cancer diagnosis.

With their ability to process information compromised by the stress and emotional impact of diagnosis, and the pressure to choose the treatment with the best chance of survival, men struggled to evaluate the treatment options presented to them and to factor long term, post-treatment, 'quality of life' issues, including sexual side effects, into their decision-making.

Hence, 'sex was kind of the last thing on my mind' (Simon).

Men unanimously agreed that during the early stages of their cancer journey, it was difficult to engage in any meaningful way with detailed technical information on the sexual side effects of treatment, including specific advice about management options and how to use sex aids:

They say 'well you're quite likely to have erectile dysfunction, but there's things we can do. We can give you a pump'. And you just think... 'Argh!, I don't even want to think about that at this stage' because you're there dealing with cancer and you're just thinking 'I don't even know how that works and I don't want you to show me'. Oh, not because you're in denial about it, but you're going 'all I have to do is just get rid of this tumour, I've gotta get rid of this cancer' and thinking about mechanical sex aids you just go 'I can't cope with that right at this moment', so there's a timing issue. (Simon) 
For the majority of men, sex occupied a relatively lowly position within the hierarchy of precedence that underpinned their treatment decision-making. Other matters were prioritised, including survival, eradicating the cancer, and (in some instances), preserving continence:

It wasn't important at the time [the sexual side effects of treatment]. Just getting rid of the cancer was the most important thing. (Edward)

Priorities are quite different, you are not thinking about sex or anything to do with it. You just want to use the loo really, without help, is all you are wanting really. (Paul)

Men were pragmatic, and viewed the changes to their sexual function as the necessary cost of their survival:

I had read then about the effects on your sex life but I said 'I would rather have a life than a sex life', that's what it comes down to. (Edward)

Paradoxically, it was only once the cancer ceased to be perceived as life threatening and the treatment decision had already been made, that men became more receptive to discussing the initial information they were given about the longer-term sexual side effects of treatment.

\section{(2) The psychology of sex is missing}


After commencing treatment, many men were ready to engage with information about, and discuss, psychosexual matters with clinicians. However, in stark contrast to the wealth of information about sexual side effects reportedly provided by clinicians during the early, treatment decision-making stage of their cancer journey, at this later stage, men reported that the sexual and emotional consequences of treatment were not routinely discussed unless they initiated the topic themselves:

There is definitely an onus on me to tell people what the problem is really. (Jon)

I had to force the issue, and when I didn't get the response I wanted, I didn't get the environment I wanted, I thought 'well right, I am going to find that resource somewhere else'. (Robert)

When clinicians did discuss sexual matters with patients, they reportedly focused too narrowly on erectile dysfunction [ED] and 'penile rehabilitation' with different treatment modalities (e.g., oral medications, penile injections, vacuum erection devices, use of a prosthesis). Penile rehabilitation can preserve erectile tissue health and minimise damage, leading to better and quicker recovery of erectile function (Chung and Gillman, 2014). However, men complained that they did not want to be offered interventions that focused exclusively on mechanical aspects of sex.

Ifelt from the ED clinic it was entirely mechanical. It was just, you know, 'this is how you do it'. It was very much the mechanics of sex. Not the combination of a relationship with a woman. (Derek) 
It [information from health care providers about the sexual side effects of treatment] was very matter of fact. It was very, 'yeah, erm ... this is what you can do'... it didn't really deal with the emotional side of it. It dealt with the mechanics of the act, but not the more complex emotions that come with it. (Derek)

This 'mechanics' versus 'emotions' contrast featured prominently across men's accounts, reflecting a distinction between communication men liked, versus communication they deemed inadequate: Men did not want to be treated as biological, emotionless systems of technically 'correctable' sexual functions., The almost exclusive focus on ED and restoring penetrative intercourse served to conceal and obstruct open discussion of men's psychosexual information and communication needs, and led men to view the medical construction of male sexuality as largely phallocentric.

Frankly it's all a bit cock-centric really, which is a narrow view of male sexuality... There is an over fixation on erectile dysfunction, because you're not a dog, you're a person. What you actually stop feeling is you stop feeling sexy ... What you want physically from someone changes so you don't have that kind of sexual feeling that is linked to getting an erection, but the erection isn't the be all and end all, you know you're not a rutting stag or some stallion being put out to stud and all that stuff and I suppose that would be the comment that I would make:... It's over willycentred, which is a funny way of putting it but it's a serious point. At the heart of it, a reduced libido effects how you feel sexually in terms of your sexual desire for someone, whether you're going to have penetrative intercourse with them or not. (Simon) 
Sexuality is not just if you can do it (Michael)

Discussion rarely extended beyond the physical aspects of treatment to help men adjust to the psychological ramifications of an altered body:

They [clinicians] weren't mindful of my mental state, how a bloke operates and why a bloke gets an erection in the first place. (Robert)

I cannot recall any psycho-sexual information whatsoever (Robert)

Most men reported significant changes to their erectile function after treatment. However, the distress associated with ED was not confined to the mechanics of penetrative sexual intercourse or biological sexual function. Instead, there were far reaching psychological and relational consequences: Men described important pieces of themselves that they perceived as damaged or incomplete as a result of treatment, including their identity, masculinity, body image, eroticism and fantasy life. They spoke of their struggle to come to terms with the all-encompassing nature of their loss:

And then it's like devastating isn't it [the sexual side effects of treatment], you just feel as though you have lost your manhood and uh it's-it's depressing in a way really. (Stan) 
I mean, you know that you're not going to... be able to get erections spontaneously, but part of your brain that says women are nice and alluring and attractive and enchanting is still there and working, so, and suddenly you feel very alone. There's this great loss. (Derek)

I've said that it's the three I's: It's impotence, incontinence and identity that they all go together really, with this condition. (Michael)

Men were clear that after commencing treatment they would have appreciated a different kind of sex talk; a more holistic, integrative discourse that reflected the myriad, complex, psychological and interpersonal ramifications of their altered physical state. Consequently men extolled the value of specialist psychosexual support:

A clinic that you can go to when you are feeling you need some help following your operation. Not just a medical clinic, a counselling clinic you know for sexual matters. (Stan)

As gatekeepers to such services, patients relied on their doctors to highlight the visibility of psychosexual support during clinical consultations. However some men reported that clinicians were less than forthcoming with this information, which in turn impacted their awareness of, and access to these resources:

They never said if you really want to go into the sexual side of things you can see a psychosexual nurse. Nobody ever tells you that. (Patrick) 
For the few men who said they were referred to a psychosexual nurse or therapist, it was evident that a more holistic approach to sexual recovery was highly valued:

I was able to talk through my problems, mainly sexual, but she [psychosexual specialist] was also a good support for the emotional rollercoaster which came after treatment, which I wasn't prepared for. (Derek)

\section{(3) Communication is not individually tailored}

Across the sample, men emphasised their need to be seen as unique individuals: 'the thing is with prostate cancer every patient is different' (Stan), 'men are all different, people are all different' (Edward). Consequently, idiosyncratic patientcentred factors strongly shaped men's psychosexual communication and information needs.. Men were clear that clinicians should be tailoring information about sex and sexuality to their individual social circumstances, beliefs, priorities, values and attitudes towards sex and sexuality, or 'recognising nuance' (Simon). However a further communication challenge reported by these men was that their unique individuality was largely overlooked by clinicians and individual tailoring of communication was negligible:

It [information about the sexual side effects of treatment] wasn't tailored towards me. Not at all I don't think. (Paul)

More problematically, some men felt that clinicians made assumptions about their psychosexual communication and information needs based on stereotypes and 
sociocultural norms. For example, they perceived that clinicians assumed that sexual matters become less important with age:

So if I had been maybe in my thirties and forties when they are expecting you to be more sexually active they would probably have maybe pushed you to [to explore the sexual side effects of treatment] as if, you know what I mean, because I am in my sixties they were probably thinking that side of things may have finished anyway. (Luke)

Although some men said that they did not wish to discuss the psychosexual impact of treatment: 'the age I am and the position I'm in, no' (Gordon, aged 77), many men were adamant that the importance they attributed to sex and sexuality did not diminish with age. Michael (aged 72) described his dismay at the 'ageism' he encountered when he voiced concerns about his erectile dysfunction during a consultation:

He [the specialist] said 'has it occurred to you, you might be too old for this sort of thing?' (laughs) I nearly punched him in the face! 'No mate!' (Michael).

Due to the heterogeneity of patient need and preference in this area, men felt that it would be helpful for doctors to broach the topic of sexuality with them, and actively negotiate the depth and breadth of coverage that is most appropriate: 
Some men think 'I am not bothered', other men put a higher priority on it, so it [sexual side effects] should be explained to any age of man unless the man says 'oh I am not interested in that'. (Edward)

But when they [clinicians] start talking about it [sex] they will know won't they whether there is any interest there or not. (Mark)

Two men in the sample identified as gay, one of whom was single. Nineteen men identified as heterosexual, three of whom were single (see Table 1). The experiences and needs of gay and heterosexual men differ in important respects (Rose, Ussher \& Perz, 2016; Ussher et al., 2016). However, men from both groups felt that treatment effects were viewed by clinicians through the lens of heteronormativity: Clinicians made assumptions about their sexual orientation and relationship status, with information about treatment side effects geared largely towards the married or cohabiting heterosexual male:

Interviewer: And do you feel like the information that you got was tailored towards you as a gay man?

Shaun: No, very general. There is still a presumption of heterosexuality.

The assumption is that you've got a partner, rightly or wrongly. (Jon)

The PC experience was often particularly difficult for gay men. Since the information they received in advance of treatment neglected gay sexuality, it was largely ineffective in helping them to prepare for, and cope with, treatment. 
As treatment progressed and they became increasingly conscious of bodily changes, the gay men in the sample were emphatic that their individual psychosexual identity and values significantly shaped the type of clinical communication they sought, or, as Robert put it, their 'gay psychosexual needs'. They craved open conversations with clinicians about how treatment may impact upon their sexual identity and relationships as gay men:

Are you straight, are you gay, are you bisexual, do you want to talk about it, if you are gay are you with somebody at the moment? Do you want them to be in the room with us? What type of sex do you have? Is sex a really important thing for you? Are you screwed up about sex? Will you miss sex once you know it is gone but you are not aware of it at the moment? That is the type of conversation I wanted my urologist to have with me. (Robert)

Although these needs were particularly salient after commencing treatment, the gay men in the sample perceived their sexual concerns to be dismissed in a pleasant a way as they [clinicians] could', with the implicit message that 'you'll just have to get used to it' (Shaun). They emphasised that alternative sexual practice and orientation tended to remain unseen and unacknowledged in clinical communication encounters. Thus, not only was clinical communication inadequately tailored to these men's individual needs, it was absent when they were actively seeking information.

The single men in the sample (both gay and heterosexual) reported that clinicians tended to presume that psychosexual issues would be less relevant to them and that they would not be engaging in sexual activity. However these men 
were emphatic that they were no less affected by the psychosexual impact of treatment than those with partners:

I have long periods in my life when I haven't had a regular partner, I haven't had a partner at all. But I feel, it's certainly seemed for me, it's a loss. (Derek).

Single men, whatever their sexual orientation, may actually represent the patient group most in need of information and support regarding the psychosexual side effects of treatment, with one man expressing a strong desire for a 'sexual psychological therapy group' (Jon):

It's [communication about psychosexual support] an absolute must in my opinion... I mean I am speaking to you as a single man...So I can just imagine other single men being in the same- a similar situation you know... No partner to sort of lean on and stuff like that. (Jon)

For unattached men, the absence of emotional support from a partner served to increase vulnerability to psychological distress as they navigated the many challenges of their cancer treatment alone. As one man plaintively reflected, 'I was there on my own' (Derek). By contrast, for men who were in an established relationship, the strong emotional bonds and foundation of support they received from their partner was cited as a key protective factor that helped them to cope with the psychosexual consequences of treatment, including ruptures to their sexual life, and facilitated their recovery: 
I wouldn't wanna do this on my own, I tell you because just being in a partnership is fantastic for getting through it. (Simon)

Oh I wouldn't like to face this alone, that must be horrendous. (Barry)

These men acknowledged that if they were not in a long term, stable relationship, they would feel ill-equipped for the physical and emotional challenges of starting and sustaining an intimate relationship whilst coping with the iatrogenic effects of treatment:

I think if you're in a secure relationship with someone who says they haven't married you for your willy you're okay in that sense and that's a very wonderful thing but ....if I was 53 and my marriage had just broken down and I wanted to get a new relationship, oh my God it would be far more significant to you because you'd be thinking about how it would affect future relationships. That's not to say I'm taking Claire [participant's wife] for granted, I'm not saying that, I'm just saying you know, there's a difference between having an established relationship and when you don't and I think that would be a very frightening thing. (Simon)

Unlike the single men in the study, men who were in established relationships described themselves as less in need of additional support to cope with the emotional ramifications of treatment: 
Being in the fortunate position I am in, my wife could fill that role. But if I hadn't got that I would have definitely been talking to those specialist nurses. (Stan)

I didn't really need it [counselling] 'cause I've got Claire [participant's wife] and a lot of good people around me I suppose. (Simon)

Ultimately men's psychosexual information and communication needs are heterogeneous and influenced by factors such as sexual orientation, relationship status, sexual motivations, values and beliefs. Consequently, men in this study articulated a need for clinicians to discuss PC treatment and its side effects within the context of their individual circumstances and for psychosexual support to be visible and readily available to those who require it.

\section{Discussion}

This study sought to advance understanding of the psychosexual information and communication challenges faced by men with PC. Three themes reveal the predominant challenges that hinder men's needs from being met.

Before treatment, men reported that they were forewarned of the potential for embodied sexual side effects and presented with information on medical treatment for ED, in line with national guidelines (NICE 2014, p.14). However, at this early stage of their cancer journey, they did not always have the cognitive reserves necessary to engage with information about sexual matters. The emotional toll of diagnosis and competing priorities meant that sex occupied a relatively lowly position within the hierarchy of precedence that underpinned men's treatment decision-making. Hence an early challenge was that it felt too soon to talk about 
sex. This finding suggests that although it is important to equip men with information about the sexual side effects of different treatments early in their cancer journey, clinicians may need to be aware of the problems men face integrating such information early on, and build additional, focussed discussions about the psychosexual consequences of treatment into later, follow-up appointments. Indeed, it may be prudent, in early appointments, for clinicians to consider and discuss with patients the likely fluctuation of their psychosexual needs and information processing abilities across the cancer timeline. This would support men to develop the capacity to take into account long-term sexual side effects and ensure treatment decisions are based on quality of life considerations as well as survival (NICE 2014).

Interestingly, findings indicate that psychosexual communication challenges may be more salient at particular points of the PC experience: In stark contrast to the wealth of information about sexual side effects reportedly provided by clinicians during treatment decision-making, men reported that later in their cancer journey, after they had commenced treatment and were ready to discuss psychosexual matters with clinicians, such matters were not routinely discussed unless men initiated the topic themselves. Further research is needed with larger samples to determine whether for some men the clinical communication challenges identified here are experienced within a sequential timeline.

Where clinicians did discuss sexual matters with patients, a second communication challenge concerned the almost exclusive focus by clinicians on a what men termed the 'mechanics' of sex, at the expense of broader, holistic discussion about the psychological and emotional consequences of treatment.. 
A number of researchers have developed therapeutic, psychoeducational, and supportive interventions to address PC patients' unmet psychosexual and relational needs (e.g., Canada, Neese and Schover, 2005; Giesler et al., 2005, Northouse et al. 2007; Robertson et al., 2014; Titta et al., 2006; Wootten et al., 2016). A variety of approaches will be important in a stepped care model for supporting men through PC (see Parahoo et al., 2015 and White et al., 2015 for reviews). However, our findings suggest that some of men's basic communication needs could be met by empowering both doctors and patients to speak openly about psychosexual matters within routine appointments (Tucker, Peters \& Speer, 2016). By optimising discussion of sexual functioning at appropriate moments during routine care, before problems develop or escalate, it may be possible to minimise distress, improve psychosexual outcomes and reduce the need for specialist interventions and referrals to psychosexual support services outside the consultation.

Research shows that clinicians are often reticent to discuss psychosexual matters with patients and their partners or carers, because such discussions have psychosocial consequences for them: they are afraid of 'opening up a can of worms' (Dyer and Das Nair, 2013; Gott et al., 2004). Hence, the narrow focus by clinicians on the 'mechanics' of sex identified by our interviewees, may make the discussion feel 'safer', and more contained.

At present, clinicians in the UK are given formal communication training as part of their medical education, which does include communication about sex (General Medical Council, 2015; Von Fragstein et al. 2008, p.1104). However, in urology and oncology specialties, training often centres on delivering bad news and minimal attention is given to other sensitive topics like sex and sexuality (Fallowfield and Jenkins, 2004; Intercollegiate Surgical Curriculum Programme, 
Urology, 2010). Existing sexual communication training programs comprise generalised 'stage' models to structure consultations, such as the four phase 'PLISSIT' model, to elicit, provide information about, solve and follow up patient's concerns (Annon 1976; Katz, 2005a, 2005b), and the six phase, 'BETTER' model (Mick, Hughes \& Cohen, 2003; Cohen, 2004, see also Brandenburg and Bitzer, 2009). However, our findings indicate that even where sexual matters are discussed within consultations, healthcare professionals may require additional support and training to instigate open communication about psychosocial aspects of sexual issues that extends beyond the mechanics of sex, to reduce the 'overmedicalization' of these concerns (Dyer and das Nair, 2013, p.2668; Forbat et al., 2012). Further research is needed with larger samples exploring clinical communication first hand, to identify precisely which interactional strategies promote or hinder patient centred communication about psychosexual matters, and to develop evidence-based resources to equip patients and doctors with the skills to confidently raise such matters during appointments.

The third communication challenge identified by interviewees concerns the perceived failure by clinicians to tailor communication to their unique needs, in line with UK guidelines (NICE, 2014, p.12). Some men felt that clinicians made judgements about their psychosexual communication needs based on their age, and this, in turn, sustained unmet needs. There is evidence to suggest that age-based presumptions may be linked to the psychosocial anxieties and vulnerabilities that healthcare professionals experience when discussing sex and sexuality with people of particular ages (Gott et al., 2004, Gott and Hinchcliffe, 2003; Hordern and Street, 2007). Our findings contribute to this literature, suggesting that skills-based training in the area of communication and psychosexual awareness may facilitate the 
proactive and permissive stance clinicians need to raise such issues with patients. Our findings also highlight the perceived lack of targeted communication strategies and interventions for gay and single men, despite the fact that these men appear to have support needs that differ from heterosexual men in long-term relationships (Blank, 2005). Traditionally a 'hidden population' in prostate cancer care (Ussher et al., 2016; Rose et al., 2016), the side effects of PC have specific meanings and consequences for gay and bisexual men's relationships, identities and sexual practices: For example, recent research reports a need by many gay and bisexual men for firmer erections for penetrative anal sex, concerns about the potential loss of anal pleasure associated with the prostate, which is considered 'the male G-spot', and the erotic and symbolic significance attached to 'visible semen exchange' (Rose et al., 2016).

Gay and bisexual men are often single, and have casual sex or multiple partners, which can have distinctive implications for the way they experience the sexual effects of PC treatment. Our research further develops this literature by demonstrating that single men (both gay and heterosexual) have elevated psychosexual support needs and survivorship concerns as they experience PC without the emotional support of an established partner. In particular, the single gay and heterosexual men in our sample identified themselves as sexual beings who are no less susceptible to the loss experience associated with PC treatment than their attached counterparts. They faced the challenge of adjusting to an altered sexual self, as well as concerns about initiating new intimate relationships in the future. Our findings therefore suggest that in addition to tackling heteronormative understandings about psychosexual matters within PC care (Rose et al., 2016), 
information on psychosexual matters should be made visible and accessible to gay and single men and sensitised towards their distinctive communication needs.

\section{Limitations}

Our methods were limited in six ways: First, our recruitment strategy is likely to have resulted in accounts derived from men treated at a handful of clinics across the North West of England. Consequently, these findings may not be transferable to other UK clinics. Second, the sample comprised men who volunteered to be interviewed. Hence, relevance of the findings to other subgroups of men with PC may be limited by self-selection bias. It is possible that those men who did not come forward either feel most inhibited at the prospect of discussing psychosexual matters with clinicians (Corbin and Morse, 2003), or least bothered about such issues It is therefore difficult to ascertain whether findings accurately reflect the level of psychosexual distress incurred as a result of treatment for PC. Third, the number of single (gay and heterosexual) men in the sample was small. To gain a fuller understanding of the psychosexual needs of these populations, further research is required with larger samples. Fourth, as the study exclusively recruited Caucasian, English speaking men, further research is needed to ascertain the degree to which the findings are transferable to more ethnically diverse populations of men whose experiences may differ from those in the present study. This is particularly important as black men are significantly more likely to receive a diagnosis of cancer than white males (Forman, 2009) and ideas and values about sex and sexuality may differ across cultures (e.g., Jankowiak, 2008). Fifth, the interviews were conducted by two young female researchers. It is possible that men may have given more candid responses, and felt more at ease, had their interviewer 
been male, or closer to their own age; a line of argument explored in research with comparable participant-researcher dynamics (e.g., Beck, Robinson \& Carlson, 2013; Letts, Tamlyn \& Byers, 2010). However, the open and expressive way in which men responded to the interview questions did not appear to indicate underdisclosure. Evidence also suggests that men may be more inclined to disclose sensitive information to female interviewers (Dindia and\& Allen, 1992; Pollner, 1998) and inhibit their disclosure with male interviewers (Charteris-Black \& Seale, 2009; O’Brien, Hunt \& Hart, 2005, p. 514). Sixth, five of the interviews were conducted in the presence of female partners. It has been argued that women's perspectives tend to be more prominent in joint interviews and the views of men can be overshadowed (Eisikovits and Koren, 2010; Seale, Charteris-Black, Dumelow, Locock, \& Ziebland, 2008). However, in the present study it was evident that the supportive presence of partners often served to encourage men to speak candidly about their feelings and experiences. This is unsurprising given that many men described their partners as being integrally involved in their PC experience and a source of emotional support.

\section{Conclusions}

Our data are preliminary and implications are contingent upon further work. However, the three communication challenges identified here are united by one overarching key message: The dynamic mix of biological, psychological and relational factors that underlie the cancer experience is complex but should be reflected in clinical communication about sex and sexuality. Findings indicate a need for clinicians to be mindful of the fine psychosexual nuances within the lives of this clinical population, and for them to tailor information and sensitise their 
communication strategy towards men's sexual orientation, relationship status, sexual motivation and values, taking into account their dynamic and idiosyncratic nature. Grounding skills-based training in communication and psychosexual awareness within patients' experiences of what it is like to talk about sexual issues within a clinical setting is central to building healthcare professionals' capacity to meet patient need and enhance survivorship.

\section{Acknowledgement}

The authors would like to acknowledge the support of an NIHR Research Design Service for the Northwest Patient and Public Involvement (PPI) Bursary, and seed corn funding awarded by the School of Psychological Sciences, University of Manchester.

\section{Contribution statement}

Speer conceived of the idea for the interview study, conducted patient and public involvement work in the community, and gained funding to support the study. McPhillips and Tucker recruited participants, conducted the interviews, and transcribed the data. Tucker contributed to study design, analysed the data in conjunction with Speer and Peters, and led the writing of the manuscript for her ClinPsyD thesis (Tucker, 2015). Speer and Peters contributed to data analysis, and commented on successive drafts. Speer produced the final version of the manuscript. 
Table 1

Baseline demographics for study participants $(N=21)$.

\begin{tabular}{|c|c|c|c|c|c|c|c|}
\hline Pseudonym & $\begin{array}{l}\text { Age at interview } \\
\text { (yrs) }\end{array}$ & Treatment & Stage of disease & Time since treatment & $\begin{array}{l}\text { Sexuality } \\
\text { (as disclosed by participants) }\end{array}$ & $\begin{array}{l}\text { Employment } \\
\text { status }\end{array}$ & $\begin{array}{l}\text { Married/ } \\
\text { Partner }\end{array}$ \\
\hline 1. Richard & 65 & $\mathrm{~B}$ & Localised & 3 years & Heterosexual & Retired & Yes \\
\hline 2. Jon & 69 & $\mathrm{RP}, \mathrm{R}$ & Locally advanced & 3 months & Heterosexual & Retired & No \\
\hline 3. Edward & 72 & $\mathrm{R}$ & Localised & 5 years & Heterosexual & Retired & Yes \\
\hline 4. Stan & 70 & $\mathrm{RP}$ & Localised & 19 months & Heterosexual & Retired & Yes \\
\hline 5. Mark and Sheila & 58 & $\mathrm{RP}$ & Localised & 2 years 5 months & Heterosexual & Retired & Yes \\
\hline 6. Michael & 74 & HT & Advanced & Ongoing & Heterosexual & Retired & Yes \\
\hline 7. Shaun & 71 & $\mathrm{R}$ & Localised & 10 years & Gay* & Retired & Yes \\
\hline 8. Nick & 72 & $\mathrm{RP}, \mathrm{R}$ & Locally advanced & 1 year 9 months & Heterosexual & Retired & Yes \\
\hline 9. Dave & 67 & $\mathrm{HT}, \mathrm{R}$ & Locally advanced & 3 years & Heterosexual & Retired & Yes \\
\hline 10. Robert & 59 & $\mathrm{RP}, \mathrm{R}, \mathrm{HT}$ & Locally advanced & 2 years 6 months & Gay* & Self-employed & No \\
\hline 11. Paul & 55 & $\mathrm{R}$ & Localised & 2 years & Heterosexual & Employed & No \\
\hline 12. Terry and Catherine & 65 & $\mathrm{RP}$ & Localised & 8 years & Heterosexual & Retired & Yes \\
\hline 13. Patrick & 78 & $\mathrm{HT}, \mathrm{R}$ & Locally advanced & Ongoing & Heterosexual & Retired & Yes \\
\hline 14. Reg & 60 & $\mathrm{R}$ & Localised & 5 years & Heterosexual & Retired & Yes \\
\hline 15. Phillip & 52 & $\mathrm{RP}$ & Localised & Ongoing & Heterosexual & Employed & Yes \\
\hline 16. Luke & 64 & $\mathrm{R}, \mathrm{HT}$ & Locally advanced & Ongoing & Heterosexual & Retired & Yes \\
\hline 17. Derek & 61 & $\mathrm{RP}$ & Localised & 1 year 1 month & Heterosexual & Retired & No \\
\hline 18. Barry and Audrey & 56 & $\mathrm{HT}, \mathrm{R}$ & Advanced & Ongoing & Heterosexual & Employed & Yes \\
\hline 19. Peter and Janet & 61 & $\mathrm{R}, \mathrm{HT}$ & Advanced & Ongoing & Heterosexual & Retired & Yes \\
\hline 20. Simon & 54 & $\mathrm{R}$ & Localised & Ongoing & Heterosexual & Self-employed & Yes \\
\hline 21. Gordon and Mavis & 77 & R, HT, RP & Advanced & Ongoing & Heterosexual & Retired & Yes \\
\hline
\end{tabular}

RP, Radical Prostatectomy; R, Radiotherapy including Brachytherapy; HT, Hormone Therapy. * Participant's terminology 


\section{References}

Annon, J. S., 1976. The PLISSIT model: A proposed conceptual scheme for the behavioural treatment of sexual problems. Journal of Sex Education and Therapy. 2(1), 1-15.

Arora, N.K., 2003. Interacting with cancer patients: the significance of physicians' communication behavior. Social Science \& Medicine. 57(5), 791-806. doi:10.1016/S0277-9536(02)00449-5

Barriball, K.L., While, A., 1994. Collecting data using a semi-structured interview: A discussion paper. Journal of Advanced Nursing. 19(2), 328-35. doi:10.1111/j.1365-2648.1994.tb01088.x

Beck, A.M., Robinson, J.W., Carlson, L.E., 2009. Sexual intimacy in heterosexual couples after prostate cancer treatment: What we know and what we still need to learn. Urologic Oncology. 27(2), 137-43. doi:10.1016/j.urolonc.2007.11.032.

Beck, A.M., Robinson, JW., Carlson, L.E., 2013. Sexual values as the key to maintaining satisfying sex after prostate cancer treatment: The physical pleasure-relational intimacy model of sexual motivation. Archives of Sexual Behaviour. 42(8), 1637-47. doi:10.1007/s10508-013-0168-z.

Blank, T. O., 2005. Gay men and prostate cancer: Invisible diversity. Journal of Clinical Oncology. 23(12), 2593-2596. doi:10.1200/JCO.2005.00.968

Boyatzis, R. E. 1998. Transforming qualitative information: Thematic analysis and code development. Thousand Oaks: Sage.

Brandenburg, U., Bitzer, J., 2009. The challenge of talking about sex: The importance of patient- physician interaction. Maturitas. 63(2), 124-127. doi:10.1016/j.maturitas.2009.03.019. 
Braun, V., Clarke, V., 2006. Using thematic analysis in psychology. Qualitative Research in Psychology. 3(2), 77-101. doi:10.1191/1478088706qp063oa

Canada, A. L., Neese, L. E., Sui, B., \& Schover, L. R., 2005. Pilot intervention to enhance sexual rehabilitation for couples after treatment for localized prostate carcinoma. Cancer. 104, 2689-2700.

Carr, S. V., 2007. Talking about sex to oncologists and about cancer to sexologists. Sexologies. 16(4), 267-272. doi:10.1016/j.sexol.2007.06.007

Charteris-Black, J., Seale, C., 2009. Men and emotion talk: Evidence from the experience of illness. Gender \& Language. 3(1), 81-113. doi:10.1558/G\&L vol 3.12009 81-113 genl.v3i1.81

Chung, E., Brock, G., 2013. Sexual rehabilitation and cancer survivorship: A state of art review of current literature and management strategies in male sexual dysfunction among prostate cancer survivors. The Journal of Sexual Medicine. 10(S1), 102-111. doi:10.1111/j.1743-6109.2012.03005.x.

Chung, E., Gillman, M., 2014. Prostate cancer survivorship: A review of erectile dysfunction and penile rehabilitation after prostate cancer therapy. The Medical Journal of Australia. 200, 582-585. doi:10.5694/mja13.11028

Cohen, M. Z,. 2004. Using the BETTER model to assess sexuality. Clinical Journal of Oncology Nursing. 8(1).

Corbin, J., Morse, J.M., 2003. The unstructured interactive interview: Issues of reciprocity and risks when dealing with sensitive topics. Qualitative Inquiry. 9(3), 335-354. doi:10.1177/1077800403251757

Department of Health, 2011. Improving outcomes: A strategy for cancer. https://www.gov.uk/government/publications/the-national-cancer-strategy (accessed 24/5/2016) 
Dindia, K., Allen, M., 1992. Sex differences in self-disclosure: A metaanalysis. Psychological Bulletin. 112(1), 106-24. doi:10.1037/0033-2909.112.1.106

Donovan, J.L., Hamdy, F.C., Lane, J.A., Mason, M., Metcalfe, C., Walsh, E., et al., 2016 Patient reported outcomes after monitoring, surgery, or radiotherapy for prostate cancer. New England Journal of Medicine. 375, 1425-1437.

Dyer, K., das Nair, R., 2013. Why don't healthcare professionals talk about sex? A systematic review of recent qualitative studies conducted in the United Kingdom. The Journal of Sexual Medicine, 10(11), 2658-2670. doi:10.1111/j.1743-6109.2012.02856.x

Eisikovits, S., Koren, C., 2010. Approaches to and outcomes of dyadic interview analysis. Qualitative Health Research. 20(12), 1642-1655. doi; $10.1177 / 1049732310376520$

Epstein, R., Street, R. L., 2007. Patient-centered communication in cancer care: Promoting healing and reducing suffering. National Cancer Institute, US Department of Health and Human Services, National Institutes of Health.

Fallowfield, L., Jenkins, V., 1999. Effective communication skills are the key to good cancer care. European Journal of Cancer. 35(11), 1592-1597. doi:10.1016/S0959-8049(99)00212-9

Fallowfield, L., Jenkins, V., 2004. Communicating sad, bad, and difficult news in medicine. The Lancet. 363(9405), 312-319.

Ferlay, J., Soerjomataram, I., Dikshit, R., Eser, S., Mathers, C., Rebelo, M. et al., 2015. Cancer incidence and mortality worldwide: Sources, methods and major patterns in GLOBOCAN 2012. International Journal of Cancer. 136(5), E359-E386. doi:10.1002/ijc.29210 
Flynn, K.E., Reese, J.B., Jeffery, D.D., Abernethy, A.P., Lin, L., Shelby, R.A. et al., 2012. Patient experiences with communication about sex during and after treatment for cancer. Psycho-Oncology. 21(6), 594-601. doi:10.1002/pon.1947.

Forbat, L., White, I., Marshall-Lucette, S., Kelly, D., 2012. Discussing the sexual consequences of treatment in radiotherapy and urology consultations with couples affected by prostate cancer. BJU International. 109(1), 98 - 103. Doi:10.1111/j.1464-410X.2011.10257.x

General Medical Council, 2015. Promoting excellence: Standards for medical education and training. http://www.gmc-uk.org/education/standards.asp/ (accessed 24/5/2016)

Giesler, R. B., Given, B., Given, C. W., Rawl, S., Monahan, P., Burns, D., Azzouz, F., Reuille, K.M., Weinrich, S., Koch, M., Champion, V., 2005. Improving the quality of life of patients with prostate carcinoma: A randomized trial testing the efficacy of a nurse-driven intervention. Cancer. 104, 752-762.

Gilbert, E., Perz, J., Ussher, J.M., 2016. Talking about sex with health professionals: The experience of people with cancer and their partners. European Journal of Cancer Care. 25, 280-293.

Gott, M., Galena, E., Hinchliffe, S., Elford, H., 2004. 'Opening a can of worms': GP and practice nurse barriers to talking about sexual health in primary care. Family Practice. 21 528-536.

Gott, M., Hinchcliffe, S., 2003. How important is sex in later life? The views of older people. Social Science \& Medicine. 56(8), 1617-28. 
Harrington, J. M., 2011. Implications of treatment on body image and quality of life, Seminars in Oncology Nursing. 27(4), 290-299. doi:10.1016/j.soncn.2011.07.007

Hordern, A.J., Street, A.F., 2007. Communicating about patient sexuality and intimacy after cancer: Mismatched expectations and unmet needs. The Medical Journal of Australia. 186(5), 224-7.

Independent Cancer Taskforce, 2015. Achieving world-class cancer outcomes: A strategy for England 2015-20. Report of the Independent Cancer Taskforce http://www.cancerresearchuk.org/about-us/cancer-taskforce/ (accessed 24/5/2016)

Intercollegiate Surgical Curriculum Programme, Urology, 2010. Breaking bad news.

https://www.iscp.ac.uk/surgical/SpecialtySyllabus.aspx?enc=jmE92GS8Jyte gbE7ZOGTwZRw8G43Ax+q35JuzZ6wKJp/Uy6ENDfonh+C1muz4tKn9X Q4n1jfKZ+aHU5nmPEf30hzUpPoMCWlhpVDzkGHUdyFT/wxfnbIsj5Gfr QWxlR9v1oDIV+Cp9QEJSbKkY/EOg==

(accessed 24/5/2016)

Jankowiak, W.R., 2008. Intimacies: Love and sex across cultures. USA: Columbia University Press.

Katz, A., 2005a. Do ask, do tell: Why do so many nurses avoid the topic of sexuality? The American Journal of Nursing. 105(7), 66-68.

Katz, A., 2005b. The sounds of silence: Sexuality information for cancer patients. Journal of Clinical Oncology. 23(1), 238-241. 
Letts, C., Tamlyn, K., Byers, E.S., 2010. Exploring the impact of prostate cancer on men's sexual well-being. Journal of Psychosocial Oncology. 28(5), 490-510. doi:10.1080/07347332.2010.498457.

Mick, J., Hughes, M., Cohen, M., 2003. Sexuality and cancer: How oncology nurses can address it BETTER, Oncology Nursing Forum. 30(S2), 152-153.

National Cancer Survivorship Initiative, 2013. Living with and beyond Cancer: Taking action to improve outcomes. Department of Health, Macmillan Cancer support and NHS Improvement.

National Institute for Health and Care Excellence, 2014. Prostate cancer: Diagnosis and treatment. Full guideline. CG175. https://www.nice.org.uk/guidance/cg175/evidence (accessed 16/5/2016)

Northouse., L.L., Mood, D.W., Schafenacker, A., Montie, J.E., Sandler, H.M., Forman, J.D., Hussain, M., Pienta, K.J., Smith, D.C., Kershaw, T., 2007. Randomized clinical trial of a family intervention for prostate cancer patients and their spouses. Cancer. 110, 2809-2818.

O'Brien, R., Hunt, K., Hart, G., 2005. 'It's caveman stuff, but that is to a certain extent how guys still operate': Men's accounts of masculinity and help seeking. Social Science \& Medicine. 61(3), 503-516. doi:10.1016/j.socscimed.2004.12.008

Oliffe, J., 2005. Constructions of masculinity following prostatectomy-induced impotence. Social Science \& Medicine. 60(10), 2249-59. doi:10.1016/j.socscimed.2004.10.016

Parahoo, K., McDonough, S., McCaughan, E., Noyes, J., Semple, C., Halstea,d E.J., et al. 2015. Psychosocial interventions for men with prostate cancer: a Cochrane systematic review. BJU International. 116(2), 174-83. 
Park, E. R., Norris, R. L., Bober, S. L., 2009. Sexual health communication during cancer care: Barriers and recommendations. The Cancer Journal. 15(1), 7477. doi:10.1097/PPO.0b013e31819587dc

Penson, D. F., Nelson, C. J., 2009. The Impact of prostate cancer diagnosis and post-treatment sexual dysfunction on quality of life. In J. P. Mulhall (Ed.), Sexual function in the prostate cancer patient (pp. 17-32). New York: Humana Press.

Pollner, M., 1998. The effects of interviewer gender in mental health interviews. The Journal of Nervous \& Mental Disease. 186(6), 369-73. doi:10.1097/00005053-199806000-00008

Prostate Cancer UK, 2012. Prostate cancer and your sex life. http://prostatecanceruk.org/media/1689186/prostate-cancer-and-your-sexlife-booklet.pdf (accessed 13/5/2016

Prostate Cancer UK, 2013. What is my risk of prostate cancer? http://prostatecanceruk.org/prostate-information/are-you-at-risk/infographicwhat-is-my-risk (accessed 18/5/2016)

Quinn, M., Babb, P., 2002. Patterns and trends in prostate cancer incidence, survival, prevalence and mortality. Part I: International comparison. BJU International. 90(2), 162-73. doi:10.1046/j.1464-410X.2002.2822.X

Robertson, J. M,. Molloy, G., Bollina, P.R., Kelly, D. M., McNeill, S.A. Forbat, L., 2014. Exploring the feasibility and acceptability of couple-based psychosexual support following prostate cancer surgery: Study protocol for a pilot randomised controlled trial. Trials. 15, 183. 
Rose, D., Ussher, J.M., Perz, J., 2016. Let's talk about gay sex: Gay and bisexual men's sexual communication with healthcare professionals after prostate cancer. European Journal of Cancer Care, DOI: 10.1111/ecc.12469.

Seale, C., Charteris-Black, J., Dumelow, C., Locock, L., Ziebland, S., 2008. The effect of joint interviewing on the performance of gender. Field Methods. 20 (2), 107-128. doi:10.1177/1525822X07313837

Speer, S. A., McPhillips, R., 2013 Patients' perspectives on psychiatric consultations in the Gender Identity Clinic: Implications for patient-centered communication. Patient Education and Counseling. 91(3), 385-391.

Stead, M. L., Brown, J. M., Fallowfield, L., Selby, P., 2003. Lack of communication between healthcare professionals and women with ovarian cancer about sexual issues. British Journal of Cancer. 88(5), 666-671. doi:10.1038/sj.bjc.6600799

Street Jr, R. L., Makoul, G., Arora, N. K., Epstein, R. M,. 2009. How does communication heal? Pathways linking clinician-patient communication to health outcomes. Patient Education \& Counseling. 74(3), 295-301.

Titta, M., Tavolini, I. M., Dal Moro, F., Cisternino, A., Bassi, P., 2006. Sexual counselling improved erectile rehabilitation after non-nerve-sparing radical retropubic prostatectomy or cystectomy: Results of a randomized prospective study. Journal of Sexual Medicine. 3, 267-273

Tucker, S. R. 2015. Uniting the body and mind in prostate cancer: A qualitative exploration of the psychosexual impact of prostate cancer treatment and related clinical communication needs. ClinPsyD thesis. School of Psychological Sciences, University of Manchester. 
Tucker S, Peters S, Speer S., 2016 Development of an explanatory model of sexual intimacy following treatment for localised prostate cancer: A systematic review and meta-synthesis of qualitative evidence. Social Science \& Medicine. 163 80-88

Ussher, J.M., Perz, J., Gilbert, E., Wong, W.K.T., Mason, C., Hobbs, K., et al.,2013. Talking about sex after cancer: A discourse analytic study of health care professional accounts of sexual communication with patients. Psychology \& Health. 28(12), 1370-90

DOI:10.1080/08870446.2013.811242

Ussher, J.M., Perz, J., Kellett, A., Chambers, S., Latini, D., Davis, I.D., et al., 2016. Health-related quality of life, psychological distress, and sexual changes following prostate cancer: A comparison of gay and bisexual men with heterosexual men. The Journal of Sexual Medicine. 13, 425-434.

Von Fragstein, M., Silverman, J., Cushing, A., Quilligan, S., Salisbury, H., Wiskin, C., 2008. UK consensus statement on the content of communication curricula in undergraduate medical education. Medical Education. 42(11), 1100-1107. doi:10.1111/j.1365-2923.2008.03137.x

Ward, J. F., Slezak, J. M., Blute, M. L., Bergstralh, E. J., Zincke, H. 2005. Radical prostatectomy for clinically advanced (cT3) prostate cancer since the advent of prostate-specific antigen testing: 15-year outcome. BJU International. 95(6), 751-756. doi:10.1111/j.1464-410X.2005.05394.x

Watson, E., Shinkins, B., Frith, E., Neal, D., Hamdy, F., Walter, F., et al., 2015. Symptoms, unmet needs, psychological well-being and health status in survivors of prostate cancer: Implications for redesigning follow-up. BJU International. 117, E10-E19. 
White, I. D., Wilson, J., Aslet, P., Baxter, A. B., Birtle, A., Challacombe, B. et al., 2015. Development of UK guidance on the management of erectile dysfunction resulting from radical radiotherapy and androgen deprivation therapy for prostate cancer. International Journal of Clinical Practice. 69(1), 106-123.

Wootten, A. C., Meyer, D., Abbott, J.M., Chisholm, K., Austin, D.W., Klein, B., et al., 2016 An online psychological intervention can improve the sexual satisfaction of men following treatment for localized prostate cancer: Outcomes of a Randomised Controlled Trial evaluating My Road Ahead. Psycho-Oncology. 1-7.

Wootten, A. C., Siddons, H.M., 2013. The psychosocial impact of prostate cancer. In A. Tewari (Ed.). Prostate cancer: A comprehensive perspective (pp. 1073-1080). London: Springer-Verlag.

Zhou, E.S., Bober, S.L., Nekhlyudov, L., Hu, J.C., Kantoff, P.W., Recklitis, C.J., 2016. Physical and emotional health information needs and preferences of long-term prostate cancer survivors, Patient Education \& Counseling. 99(12), 2049-2054. 
Online Supplement

Interview guide

Part one: Background

1. What is your understanding of the stage of the treatment process that you are at right now? [E.g. PSA result? Remission? More treatment required? How long have you been having treatment/when did treatment end?]

2. What type of treatment have you had? [Where have you been seen? Have you had operations? Active monitoring/surveillance/watchful waiting, removal or the prostate gland, radiotherapy to the prostate, hormone therapy, cryotherapy (destroying cancer cells by freezing them), high intensity focused ultrasound therapy, brachytherapy (internal radiotherapy) ProtecT clinical trial]

3. Who have you seen or spoken to about your treatment to date? [GP, consultants, nurses, specialist nurses?]

Part two: General communication experiences

4. Before you spoke to clinicians about your PC, what expectations, if any, did you have about what communicating with them might be like? [e.g. easy, comfortable, difficult?]

5. What expectations did you have, if any, about the information you might receive? [e.g. type/depth/topics covered /different sources of information?]

6. Have you looked for any information about prostate cancer yourself? [If so what did you hope to find? What did you find and where? How useful has this been?]

7. Could you tell me a bit about your experiences of communication during your appointments with the consultants or other doctors? [Did they put you ease? What kinds of questions did they ask you? What was the consultant's or other doctors' communication style like? Did you have the opportunity to ask doctors questions?]

8. Could you tell me a bit about your experiences of communication during your appointments with the nurses? [Prompts as for $Q$ 7]

9. 10. Could you describe any particularly positive experiences of communication with the doctors or nurses? [What made these positive experiences?]

10. Could you describe any particularly negative experiences of communication with the doctors or nurses? [What made these negative experiences?]

11. How would you sum up your experiences of communication with doctors and nurses in general?

12. What, if anything, do you think could be done to improve communication with doctors and nurses?

Part three : Experiences of communication about the sexual side effects and emotional impact of treatment

13. Before you spoke to the doctors and nurses, what did you know about the possible sexual side effects of treatment? [What about the emotional impact of treatment - e.g., its effect on your mood, wellbeing etc.]

14. What expectations did you have, if any, about what it might be like communicating with the doctors and nurses about the sexual side effects of treatment? [How about your expectations of communication about the effects of treatment on how you might feel in yourself?]

15. What expectations did you have, if any, about the information you might receive about the sexual side effects of treatment? [e.g., type/depth/topics covered (side effects, the 
emotional impact of treatment, the impact on your relationships?).

16. Have you looked for any information about the sexual side effects of prostate cancer yourself? [What did you hope to find? What did you find and where? How useful has this been?]

17. Did anyone discuss the sexual side effects of treatment with you? [Such as possible impotence, changes to the shape of the genitals (penile atrophy), feminising effects of the hormone treatments, emotional impact of treatment on you and your sex life/current/future relationships. Who discussed these issues with you? GP? Consultants? Specialist nurses?]

18. Could you tell me a bit about your experience of communicating with consultants or other doctors about sexual issues? [Who raised the topic first? How did you feel discussing this? Can you give me an example? To what extent did they make you feel supported emotionally? Did the doctors you spoke to about these issues seem comfortable/uncomfortable? Can you give me an example? How would you describe their communication style? How often did you discuss these issues with the consultants/other doctors?]

19. Could you tell me a bit about your experience of communicating with nurses about sexual issues? [Prompts as for Q18]

20. Could you describe any particularly positive experiences of communicating with doctors or nurses about the sexual side effects of treatment? [What made those experiences positive?]

21. Could you describe any particularly negative experiences of communicating with doctors or nurses about the sexual side effects of treatment? [What made those experiences negative?]

22. (If applicable) After your treatment had ended what was your experience, if any, of follow-up for the sexual side effects of treatment? [If you were given a particular kit/any kind of therapy/drugs to deal with sexual side effects, what was this? Did you feel well supported by clinicians with this? If so by who? Did they request your feedback on experiences of this?]

23. How did you feel about the amount and quality of information you were given about the sexual side effects of treatment? [Were all the topics that you wanted to find out about covered? Was there too much of anything? What, if anything, was missing? Did you feel able to ask questions about the sexual side effects of treatment? And disclose any concerns you had? How was the timing of the information you received? Was it about right/delivered in a timely fashion (e.g. before any problems arose with sexual functioning)?]

24. (If the participant has not spoken with clinicians about sexual issues) Did you want to discuss the sexual side effects of treatment with any of the clinicians you have seen to date? [Why do you think you have not been able to discuss these issues? Not had the chance? Not wanted to bring the topic up yourself? Tried but failed to bring the topic up? Clinician did not want to discuss this? Been told that you should discuss this with someone else? Did you know of other sources of information about the sexual side effects of treatment? What, effect, if any, did not being able to discuss sexual issues with clinicians have on you?]

25. How would you sum up your experiences of communicating with the doctors and nurses about the sexual side effects of treatment? [What about the emotional impact of treatment?]

26. What, if anything, do you think could be done to improve communication with clinicians about the sexual side effects of treatment? [What about the emotional impact of treatment? Can you describe how you think this might have helped with how you were feeling?] 